\title{
Formulation and Evaluation of Nisoldipne Sublingual Tablets Using Pullulan \& Chitosan for Rapid Oromucosal Absorption
}

\author{
Vivekanand K. Chatap*, Abhishek R. Maurya, Prashant K. Deshmukh, Laxmikant R Zawar \\ Department of Pharmaceutics \& Industrial Pharmacy, H.R Patel Institute of Pharmaceutical Education and Research, \\ Shirpur, Maharashtra, India- 425405 \\ Corresponding Author: chatap@rediffmail.com
}

Copyright @ 2013 Horizon Research Publishing All rights reserved.

\begin{abstract}
Nisoldipine (NSD) is a calcium channel blocker used for treatment of angina pectoris, hypertension and congestive heart failure etc. It belongs to BCS class-II i.e., low solubility \& low bioavailability (3.7 to $8.4 \%$ ) due to extensive pre-systemic metabolism of NSD. Therefore, this research work was carried out with aim to improve solubility and bioavailability. NSD sublingual tablets were prepared by direct compression method with two biodegradable polymer as major components, pullulan as solubility enhancer \& chitosan used to reduce flushing action of saliva and further evaluated pre \& post-compression parameters, in-vitro drug release study and characterised by differential scanning calorimetry (DSC), powder X-ray diffraction (PXRD) \& Fourier transform infrared spectroscopy (FTIR). It was observed that, formulation F3 containing $3 \% \mathrm{w} / \mathrm{w}$ of pullulan and $4 \% \mathrm{w} / \mathrm{w}$ chitosan showed satisfactory results with disintegration time of 34 second, wetting time of 20 second and dissolution (98.45\%) in $45 \mathrm{~min}$. The DSC, XRD \& FTIR studies showed no interaction between drug and polymer or with other additives. For rapid absorption and high bioavailability, with subsequent almost immediate onset of pharmacological effect. From this study, It can be concluded that, drug having low solubility and low bioavailability due to pre-systemic metabolism can be improve by cost effective, easy to scale up sublingual oro-mucosal approach.
\end{abstract}

Keywords Nisoldipine, Sublingual Tablet, Pullulan, Chitosan and Oromucosal Absorption

\section{Introduction}

Nisoldipine

[( \pm )-3-isobutyl-5-methyl-1,4-dihydro-2,6-dimethyl-4-(2-nitr ophenyl) pyridine-3,5-dicarbox-ylate (Fig 1)] is a calcium antagonist of the 1,4- dihydropyridine family with non-symmetrical ester functions belong to antihypertensive category drug, which reduces vascular resistance, blood pressure by inhibiting calcium uptake by the myocardium and smooth muscle cells. NSD has poor solubility, high permeability and high hepatic metabolism (1) belonging to Class II of biopharmaceutical classification system (BCS) and biopharmaceutical drug disposition system (BDDCS) and used for the treatment of angina pectoris, hypertension and congestive heart failure (2). It has a low systemic bioavailability (3.7 to $8.4 \%$ ) due to extensive pre-systemic metabolism. Sublingual administration can offer an attractive and promising alternative route of administration of drug with low bioavailability (3). An advantage of the sublingual drug delivery system, drug can be directly absorbed into systemic circulation to avoid enzymatic degradation in the gut and liver. Additionally, thin sublingual mucosa (about $190 \mu \mathrm{m}$ compared to $500-800 \mu \mathrm{m}$ of the buccal mucosa) and availability of plenty of blood supply at the sublingual region allows excellent drug penetration (absorption) to attain high plasma drug concentration with a rapid onset of action. A well-known example nitro-glycerine drug used for the treatment of acute angina (4). One problem related with sublingual drug delivery is the fact that the patient does have a tendency to involuntarily swallow liquids greater than $200 \mu \mathrm{L}$ and rapid removal of drug owing to the flushing action of saliva. Because of the involuntary swallowing of the drug, it is removed from the sublingual cavity and enters the gastrointestinal tract. To overcome this disadvantage, dosage form is needed to be in contact with sublingual mucosa for prolonged time $\&$ this can be done by adhesion of the dosage form to the moist surface of mucosa and resistance to the flushing action of saliva. To avoid flushing action \& to retain dosage form for long time, bioadhesive polymer, chitosan was used in formulations. Since NSD is a drug of potential interest but suffers from challenging problems like low aqueous solubility, an attempt was made to enhance the solubility using pullulan \& PEG 4000. Pullulan is a non-ionic polysaccharide, having several advantages as a macromolecular drug carrier, highly water-soluble and non-toxic, multiple hydroxyl groups that 
can readily be chemically modified, lacks immunogenicity, and useful as a plasma expander $(5,6)$. PEG polymers are widely used for their low melting point, low toxicity, wide drug compatibility and hydrophilicity (7-12). The present study attempts to enhance the solubility of NSD using highly water-soluble pullulan and formulation of sublingual tablets by direct compression method to avoid the extensive pre-systemic metabolism.

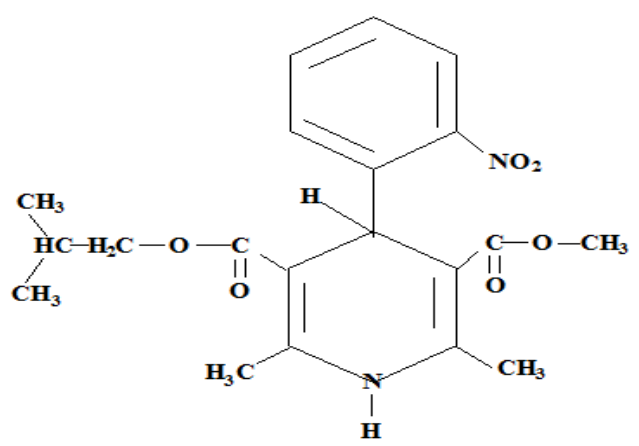

Figure 1. Structure of Nisoldipine

\section{Materials and Methods}

Nisoldipine (NSD) was obtained as a gift sample from Emcure Pharmaceutical Ltd., Pune (India). Pullulan (manufactured from Hayashibara, Okayama, Japan) was obtained from Gangwal Chemical Pvt. Ltd, Mumbai. Chitosan were purchased from Aldrich Chemistry, Bangalore. Sodium Starch Glycolate (SSG) and Mannitol were obtained from loba chemie Pvt. Ltd., Mumbai; while Mannose, Talc and Magnesium stearate were purchased from S.D Fine chemicals ltd, Mumbai, India. All other materials and reagents used were of analytical grade of purity.

\section{Preparation of Nisoldipine Sublingual Tablets}

Table 1. Composition of Nisoldipine Sublingual Tablets.

\begin{tabular}{|c|c|c|c|c|c|c|c|}
\hline Ingredients (\%) & \multicolumn{7}{|c|}{ Formulations } \\
\hline & F0 & F1 & F2 & F3 & F4 & F5 & F6 \\
\hline Nisoldipine & 10 & 10 & 10 & 10 & 10 & 10 & 10 \\
\hline Pullulan & 0 & 1 & 2 & 3 & 4 & 5 & 6 \\
\hline Chitosan & 0 & 6 & 5 & 4 & 3 & 2 & 1 \\
\hline PEG-4000 & 10 & 10 & 10 & 10 & 10 & 10 & 10 \\
\hline $\begin{array}{c}\text { Sodium Starch } \\
\text { Glycolate }\end{array}$ & 5 & 5 & 5 & 5 & 5 & 5 & 5 \\
\hline Mannitol & 69 & 62 & 62 & 62 & 62 & 62 & 62 \\
\hline Mg. Stearate & 2 & 2 & 2 & 2 & 2 & 2 & 2 \\
\hline Talc & 2 & 2 & 2 & 2 & 2 & 2 & 2 \\
\hline Mannose & 2 & 2 & 2 & 2 & 2 & 2 & 2 \\
\hline Total (mg) & 100 & 100 & 100 & 100 & 100 & 100 & 100 \\
\hline
\end{tabular}

The various formulations of NSD sublingual tablets were prepared by using direct compression method. Accurately weighed amount of the NSD and all additives were homogeneously blended after passing through $500 \mu \mathrm{m}$ screen sieve. Then, PEG-4000 was added to the mixture for further grinding for $10 \mathrm{~min}$. The powder blend was subjected to compression into tablet using 8 station single-punch tablet machine (Mini Press-II MT, Rimek, Karnavati). Compositions of each formulation are given in Table 1

\section{Evaluation of Nisoldipine Sublingual Tablets}

\section{Evaluation of pre-compression parameters of powder}

Prior to compression, powder were evaluated for their flow and compressibility parameters. Flow properties of powder were determined by angle of repose method. Compressibility index of powder were determined by Carr's index and Hauser ratio (13-14).

\section{Angle of repose}

Angle of repose $(\boldsymbol{\theta})$ was determined using funnel method. The blend was poured through a funnel that can be raised vertically until a maximum cone height (h) was obtained. The radius of the heap (r) was measured and angle of repose was calculated.

$$
\theta=\tan -1 h / r
$$

\section{Bulk Density}

Bulk density is defined as the mass of powder divided by bulk volume. It is calculated according to the equation,

\section{$L B D=$ Weight of the powder/Volume of the packing}

A sample of about $10 \mathrm{gm}$ was poured into $100 \mathrm{ml}$-graduated cylinder. The cylinder was dropped at 2 -second intervals onto a hard wooden surface three times, from a height of one inch. The volume was recorded and the bulk density was calculated.

\section{Tap Density}

Tap bulk density (TBD) of disintegrant was determined using USP tap density tester at 750 taps. Disintegrant (10g) was poured into calibrated measuring cylinder $(100 \mathrm{ml})$ and change in volume was noted before and after tapping. TBD was calculated using following equation,

\section{$T B D=$ Weight of the powder/Tapped volume of the packing}

\section{Compressibility index}

The simplest way of measurement of free flow property of powder is compressibility, an indication of the ease with which a material can be induced to flow is given by $\%$ 
compressibility that is calculated as follows:

$$
C=(\rho t-\rho b) / \rho t \times 1 \quad 0
$$

$\rho t$ - Tapped density,

$\rho b$ - Untapped bulk density

\section{Hausner's ratio}

Hausner's ratio is an index of ease of powder flow; it is calculated by following formula.

$$
H=\rho t / \rho b
$$

H- Hausner's Ratio

$\rho t$ - Tapped density,

$\rho b$-Untapped bulk density

\section{Evaluation of post-compression parameters of tablets}

\section{Tablet Thickness}

Dimension of the tablets was measured by using a calibrated dial calliper. Six tablets of each formulation were picked out randomly and its thickness was measured individually (15-16).

\section{Weight Variation Test}

The procedure described in Indian Pharmacopoeia (IP, 1996) (17) was employed to determine weight variation of tablets. Ten tablets were randomly selected from each batch and weighed on an electronic balance and mean weight was taken. Each tablet was then weighed individually and standard deviation in weight was calculated for each batch (18).

\section{Tablet Hardness}

Six tablets were randomly selected from each batch and hardness of tablets was determined by using Monsanto hardness tester. The mean values and standard deviation for each batch were calculated (16). The hardness of optimised batch F3 was carried out by Texture analyzer (Texture Pro CT V1.4 Build 17, Brookfield).

\section{Tablet Friability}

Friability indicates the ability of a tablet to withstand mechanical shocks while handling. Friability of tablets were determined using Roche Friabilator and is expressed in percentage (\%). Ten tablets were initially weighed $\left(\mathrm{W}_{\text {initial }}\right)$ and placed into the friabilator. The friabilator was operated at $25 \mathrm{rpm}$ for 4 minutes or run up to 100 revolutions and then the tablets were weight again $\left(\mathrm{W}_{\text {final }}\right)$. The loss in tablet weight due to abrasion or fracture was the measure of tablet friability. Percent friability (f) was calculated by using the following formula (16).

$$
f=\left(W_{\text {initial }}\right)-\left(W_{\text {final }}\right) \div W_{\text {initial }} \times 100
$$

$\%$ friability of less than $1 \%$ is considered acceptable

\section{Wetting Time}

The wetting time and capillarity of oral dispersible tablets were measured by a conventional method. Tablet was placed in a petridish containing $10 \mathrm{ml}$ water at room temperature and the times for complete wetting of tablets were recorded.

\section{Drug Content Uniformity}

Three tablets were powdered and weigh accurately equivalent to $80 \mathrm{mg}$ of NSD and transferred into a $100 \mathrm{ml}$ volumetric flask. Initially, $10 \mathrm{ml}$ of methanol was added and shaken for 10 minutes. Then, the volume was made up to 100 $\mathrm{ml}$ with methanol. Subsequently, the solution in the volumetric flask was filtered, and $1 \mathrm{ml}$ of the filtrate was suitably diluted and analysed for drug content using UV-spectrophotometer (UV-1700 Pharmaspec, Shimadzu, double beam spectrophotometer) at $\lambda=238 \mathrm{~nm}$.

\section{Disintegration Test}

The disintegration time was determined by using USP tablet disintegration test apparatus using $900 \mathrm{ml}$ of distilled water without disk. Time taken by tablets (sec) for complete disintegration of the tablets until no mass remaining in apparatus was measured (15-16).

\section{In-Vitro Drug Release Study}

The in-vitro drug release study of NSD from the tablets were carried out using USP dissolution test apparatus type-II Paddle Method (Dissolution test TDT-08L plus, Electrolab, USP) in $900 \mathrm{ml}$ of dissolution medium (phosphate buffer $\mathrm{pH}$ 6.8 ) at $37 \pm 0.5^{\circ} \mathrm{C}$ temperature and rotated at $60 \mathrm{rpm}$ (19). A 5 $\mathrm{ml}$ aliquot of dissolution medium was withdrawn at specified time intervals and immediately replaced with an equal volume of fresh medium. Samples were suitably diluted and analysed for percent drug release by using UV spectrophotometer (Shimadzu UV-1700 Pharmaspec, Shimadzu, double beam spectrophotometer) at $\lambda=238 \mathrm{~nm}$. All the tests were carried out in triplicate (18).

\section{Characterization of Nisoldipine sublingual tablets}

\section{Differential Scanning Calorimetry (DSC)}

DSC scan of pure drug, pullulan, chitosan, PEG 4000 and final optimized batch $\mathrm{F} 3$ were obtained by a differential scanning calorimeter (DSC 60, Shimadzu, Japan) at a heating rate of $10{ }^{\circ} \mathrm{C} / \mathrm{min}$ from 30 to $300{ }^{\circ} \mathrm{C}$ in nitrogen atmosphere

\section{$\mathrm{X}$-ray powder diffraction (XRD)}

The diffraction pattern of pure NSD and final optimized batch F3 tablet was evaluated by using an X-ray powder diffractometer (Bruker AXS D8, Advance diffractometer) to assess the polymorphic state. Each diffractogram was recorded from 3 to $150^{\circ}(2 \theta)$ at a scanning speed of $3^{0} / \mathrm{min}$ and using $\mathrm{Si}(\mathrm{Li}) \mathrm{PSD}$ detector. $\mathrm{Cu} \mathrm{K} \alpha$ radiation was used as the $\mathrm{X}$-ray source at a wavelength $1.5406 \mathrm{~A}^{0}$; this was 
operated at a voltage of $40 \mathrm{kV}$ and a current of $35 \mathrm{~mA}$.

\section{FTIR spectroscopy}

Fourier-transformed infrared (FTIR) spectra of pure drug, pullulan, chitosan, SSG and final optimized batch F3 tablet were obtained using an FTIR spectrometer (IR AFFINITY-1 $\mathrm{CE}$, Shimadzu, Japan) equipped with a pyroelectric detector. Data were acquired using IR solution software. The spectra were measured over the range $4000-400 \mathrm{~cm}^{-1}$ with an instrument resolution of $4 \mathrm{~cm}^{-1}$. Each individual spectrum was an average of 45 scan.

\section{Results and Discussion}

El Maghraby GM et.al.,were prepared nisoldipine fast disintegrating tablets using hydroxypropyl methyl cellulose E5 (HPMC), polyvinylpyrrolidone (PVP), Pluronic F68 or polyethylene glycol 6000 (PEG 6000) by solid dispersion method (20) and Chopra S et.al., were prepared phospholipid bearing pellets for intra-oral administration for improvement of bioavailability of NSD (21). In this research work, two biodegradable polymers pullulan was used as the solubility enhancer reported earlier by Maurya et al.,(22) and chitosan has good bioadhesion to the moist surface of mucosa and resistance to the flushing action of saliva. The natural biodegradable polymers are more attractive comparing with the synthetic ones for their good biocompatibility.
Nisoldipine sublingual tablets were prepared by direct compression method with pullulan to enhance solubility of NSD (1-6\%) \& chitosan to reduce flushing action of saliva in different ratio (6-1\%). The concentrations of pullulan were increase the solubility of NSD and chitosan were increasing binding property of blend. A total of six formulations and a control formulation F0 (without Pullulan and chitosan) were designed. The flow properties of the powder blend are important for the uniformity of mass of the tablets; the flow of the powder blend was analysed before compression into tablets. Angle of repose $(\leq 19.36)$, bulk density $(\leq 1.3)$, tapped density $(\leq 1.5)$, compressibility index $(\leq 18.24)$ and low Hausner's ratio $(\leq 1.19)$ values indicated a relatively good flowability of powder mixture (Table 2). The post compression parameters such as hardness, friability, thickness, wetting time, weight variation, disintegration time and drug content are shown in Table 3. As the tablet powder blend was free flowing, tablets produced were of uniform weight with acceptable weight variation in the range from $99.98 \mathrm{mg}$ to $102.1 \mathrm{mg}$ due to uniform die fill. Hardness $(2.0-2.68 \mathrm{~kg} / \mathrm{cm} 2)$ and friability loss $(0.30-0.75 \%)$ indicated that tablets had a good mechanical resistance. Drug content was found to be high $(\geq 99.8 \%)$ in all the tablet formulations. Wetting time was found to be in the range of $14-90 \%$. Disintegration time of sublingual tablets was found to be $\leq 75$ sec. It was observed that wetting time and disintegration time decreases with increase in concentration of pullulan.

Table 2. Pre-Compression Parameters of Nisoldipine Sublingual Tablets

\begin{tabular}{|c|c|c|c|c|c|}
\hline Formulations & $\begin{array}{c}\text { Angle of repose }(\theta) \\
\pm \mathrm{SD}(\mathrm{n}=3)\end{array}$ & $\begin{array}{c}\text { Bulk Density } \\
(\%) \pm \mathrm{SD}(\mathrm{n}=3)\end{array}$ & $\begin{array}{c}\text { Tapped Density } \\
(\%) \pm \mathrm{SD}(\mathrm{n}=3)\end{array}$ & $\begin{array}{c}\text { Compressibility (\%) } \pm \\
\mathrm{SD}(\mathrm{n}=3)\end{array}$ & $\begin{array}{c}\text { Hausner's ratio (\%) } \\
\pm \mathrm{SD}(\mathrm{n}=3)\end{array}$ \\
\hline $\mathrm{F} 0$ & $19.36(1.14)$ & $1.3(0.20)$ & $1.59(0.32)$ & $18.24(1.23)$ & $1.19(0.8)$ \\
\hline $\mathrm{F} 1$ & $15.57(1.32)$ & $1.28(0.23)$ & $1.1(0.18)$ & $14.41(1.29)$ & $1.17(0.5)$ \\
\hline F2 & $13.28(1.36)$ & $1.29(0.21)$ & $1.48(0.25)$ & $13.34(1.14)$ & $1.14(0.7)$ \\
\hline F3 & $10.35(1.21)$ & $1.25(0.17)$ & $1.15(0.19)$ & $10.12(1.02)$ & $1.01(0.6)$ \\
\hline F4 & $15.14(1.43)$ & $1.3(0.18)$ & $1.13(0.16)$ & $13.64(1.47)$ & $1.11(0.8)$ \\
\hline F5 & $14.35(1.53)$ & $1.1(0.13)$ & $0.98(0.12)$ & $13.40(1.52)$ & $1.12(0.5)$ \\
\hline F6 & $12.81(1.10)$ & $1.1(0.12)$ & $0.94(0.11)$ & $14.23(1.64)$ & $1.15(0.3)$ \\
\hline
\end{tabular}


Table 3. Post-Compression parameters of Nisoldipine sublingual tablets

\begin{tabular}{|c|c|c|c|c|c|c|c|}
\hline \multirow{2}{*}{ Formulations } & \multicolumn{7}{|c|}{ Parameters } \\
\cline { 2 - 8 } & $\begin{array}{c}\text { Hardness } \\
(\mathrm{kg} / \mathrm{cm} 2) \pm \\
\mathrm{SD}(\mathrm{n}=3)\end{array}$ & $\begin{array}{c}\text { Friability }(\% \\
\mathrm{w} / \mathrm{w}) \pm \mathrm{SD} \\
(\mathrm{n}=3)\end{array}$ & $\begin{array}{c}\text { Thickness } \\
(\mathrm{mm}) \pm \mathrm{SD} \\
(\mathrm{n}=3)\end{array}$ & $\begin{array}{c}\text { Wetting Time } \\
(\mathrm{Sec}) \pm \mathrm{SD} \\
(\mathrm{n}=3)\end{array}$ & $\begin{array}{c}\text { Weight } \\
\text { Variation } \pm \mathrm{SD} \\
(\mathrm{n}=3)\end{array}$ & $\begin{array}{c}\text { Disintegrat-ion } \\
\text { Time }(\mathrm{Sec}) \pm \mathrm{SD} \\
(\mathrm{n}=3)\end{array}$ & $\begin{array}{c}\text { Drug Content } \\
(\%) \pm \mathrm{SD}(\mathrm{n}=3)\end{array}$ \\
\hline F0 & $2.68 \pm 0.6$ & $0.75 \pm 0.7$ & $2.10 \pm 0.2$ & $90 \pm 0.8$ & $100.8 \pm 0.7$ & $75 \pm 0.7$ & $100.7 \pm 0.6$ \\
\hline F1 & $2.55 \pm 0.4$ & $0.56 \pm 0.6$ & $2.06 \pm 0.1$ & $32 \pm 0.6$ & $100.5 \pm 0.6$ & $60 \pm 0.4$ & $100.2 \pm 0.7$ \\
\hline F2 & $2.48 \pm 0.3$ & $0.46 \pm 0.8$ & $2.04 \pm 0.3$ & $26 \pm 0.4$ & $101.1 \pm 0.5$ & $45 \pm 0.6$ & $99.9 \pm 0.3$ \\
\hline F3 & $2.10 \pm 0.2$ & $0.34 \pm 0.3$ & $2.01 \pm 0.1$ & $20 \pm 0.3$ & $100.2 \pm 0.2$ & $34 \pm 0.5$ & $100.1 \pm 0.4$ \\
\hline F4 & $2.42 \pm 0.5$ & $0.42 \pm 0.5$ & $2.07 \pm 0.6$ & $18 \pm 0.5$ & $102.1 \pm 0.6$ & $30 \pm 0.3$ & $99.8 \pm 0.6$ \\
\hline F5 & $2.38 \pm 0.4$ & $0.48 \pm 0.7$ & $2.05 \pm 0.5$ & $16 \pm 0.2$ & $99.98 \pm 0.5$ & $26 \pm 0.5$ & $100.0 \pm 0.4$ \\
\hline F6 & $2.35 \pm 0.6$ & $0.51 \pm 0.4$ & $2.01 \pm 0.3$ & $14 \pm 0.1$ & $100.1 \pm 0.4$ & $20 \pm 0.2$ & $101.0 \pm 0.1$ \\
\hline
\end{tabular}

\section{DSC Study}

Fig 2 displays of DSC scans pure NSD, pullulan, chitosan, PEG-6000 and optimized batch F3. NSD displayed endothermic peak at $150.8{ }^{\circ} \mathrm{C}$ corresponding to its melting point, while pullulan, chitosan, PEG-4000 and final optimised batch $\mathrm{F} 3$ exhibited $104.2{ }^{0} \mathrm{C}, 134.6{ }^{\circ} \mathrm{C}, 59.9{ }^{\circ} \mathrm{C}, 103.8{ }^{\circ} \mathrm{C}$ respectively. The thermogram of $\mathrm{F} 3$ showed significantly decreased and reduction in peak intensity, suggesting that the crystallinity of NSD is greatly reduced, which may be due to the presence of pullulan, chitosan, PEG-4000 and SSG.

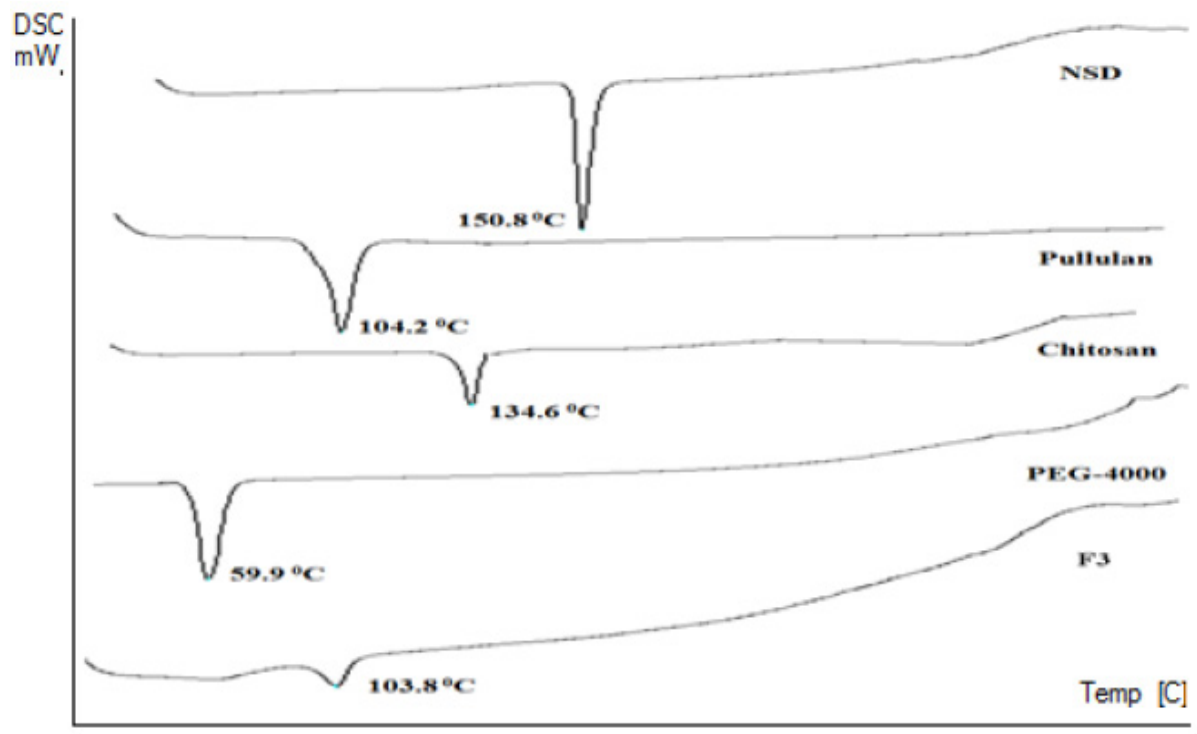

Figure 2. DSC of NSD, Pullulan, Chitosan, PEG-4000 and F3 batch tablet

\section{XRD Study}

XRD study the physicochemical characteristics of NSD and optimised batch tablet F3, X-ray diffraction measurements were conducted. The XRD of pure NSD (Fig 3) exhibited sharp, highly intense and less diffused peaks indicating the crystalline nature of drug. It showed sharp diffraction peaks at $2 \theta$ degree equal to $9.31^{\circ}, 11.29^{0}, 12.44^{0}, 18.88^{0}, 22.58^{\circ}$, and $27.24^{0}$. XRD of optimised batch F3 demonstrated diffused and low intensity peak at $2 \theta$ degree equal to $9.72^{0}, 11.30^{\circ}, 12.41^{\circ}$, $18.84^{\circ}, 22.58^{\circ}$ and $27.25^{\circ}$. This result confirms that crystallinity of NSD is reduced. 


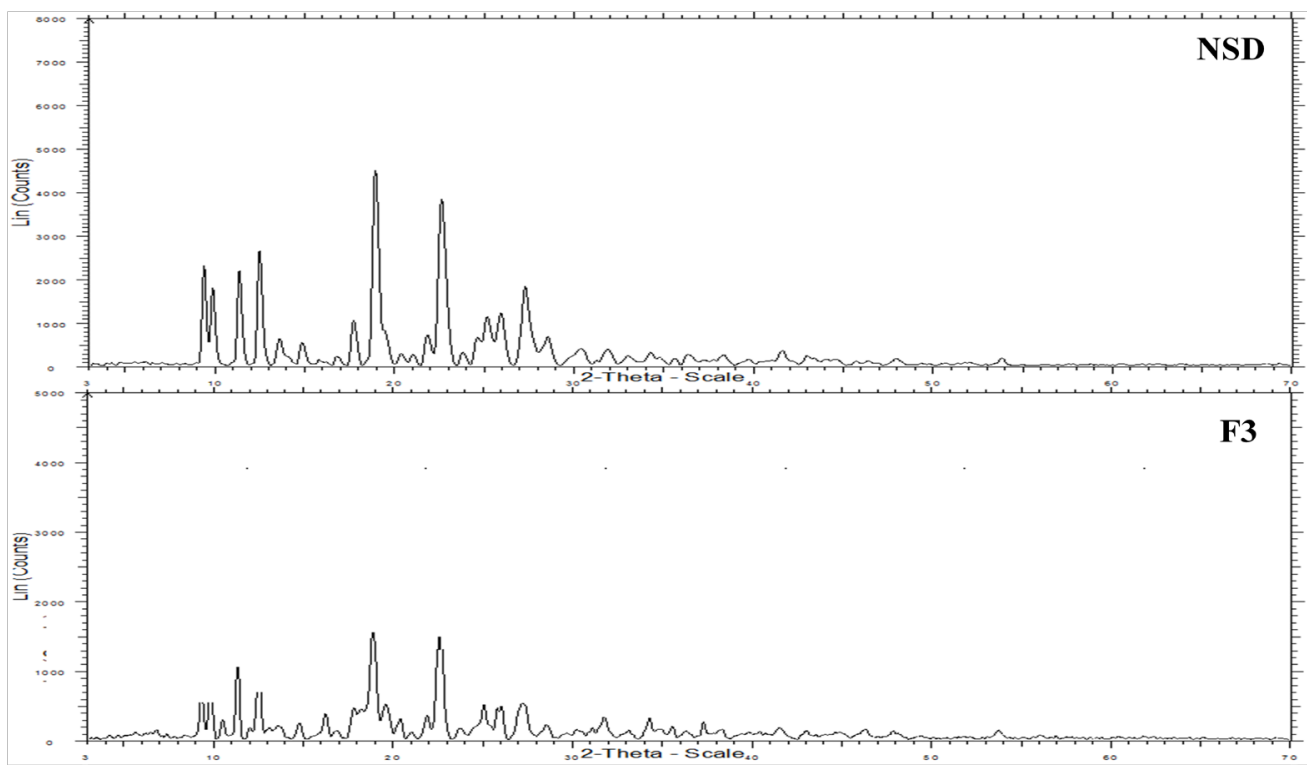

Figure 3. XRD of NSD and formulation F3

\section{FTIR Study}

In order to further study whether NSD undergoes a polymorphic change during the preparation of the complex and to test for possible intermolecular interactions between Nisoldipine and the polymer, FTIR was used. Fig 4 shows the IR spectra of pure NSD exhibits a sharp peak characteristic of the N- H stretching vibration (A) at $3320 \mathrm{~cm}^{-1}$ and a band with main peak at $1700 \mathrm{~cm}^{-1}$ indicative of the $\mathrm{C}=\mathrm{O}$ stretch $(\mathrm{C})$ of the esteric group, showing its crystalline nature. The absorption bands at 3000 $\mathrm{cm}^{-1}$ denotes $\mathrm{C}-\mathrm{H}$ stretch (B), at $1120 \mathrm{~cm}^{-1}$ and $1225 \mathrm{~cm}^{-1} \mathrm{~cm}$ for ether (C-O) absorption (E), while two strong absorption peaks at $1550 \mathrm{~cm}^{-1}$ and $1350 \mathrm{~cm}^{-1}$, suggests nitro $\left(\mathrm{NO}_{2}\right)$ group (D).

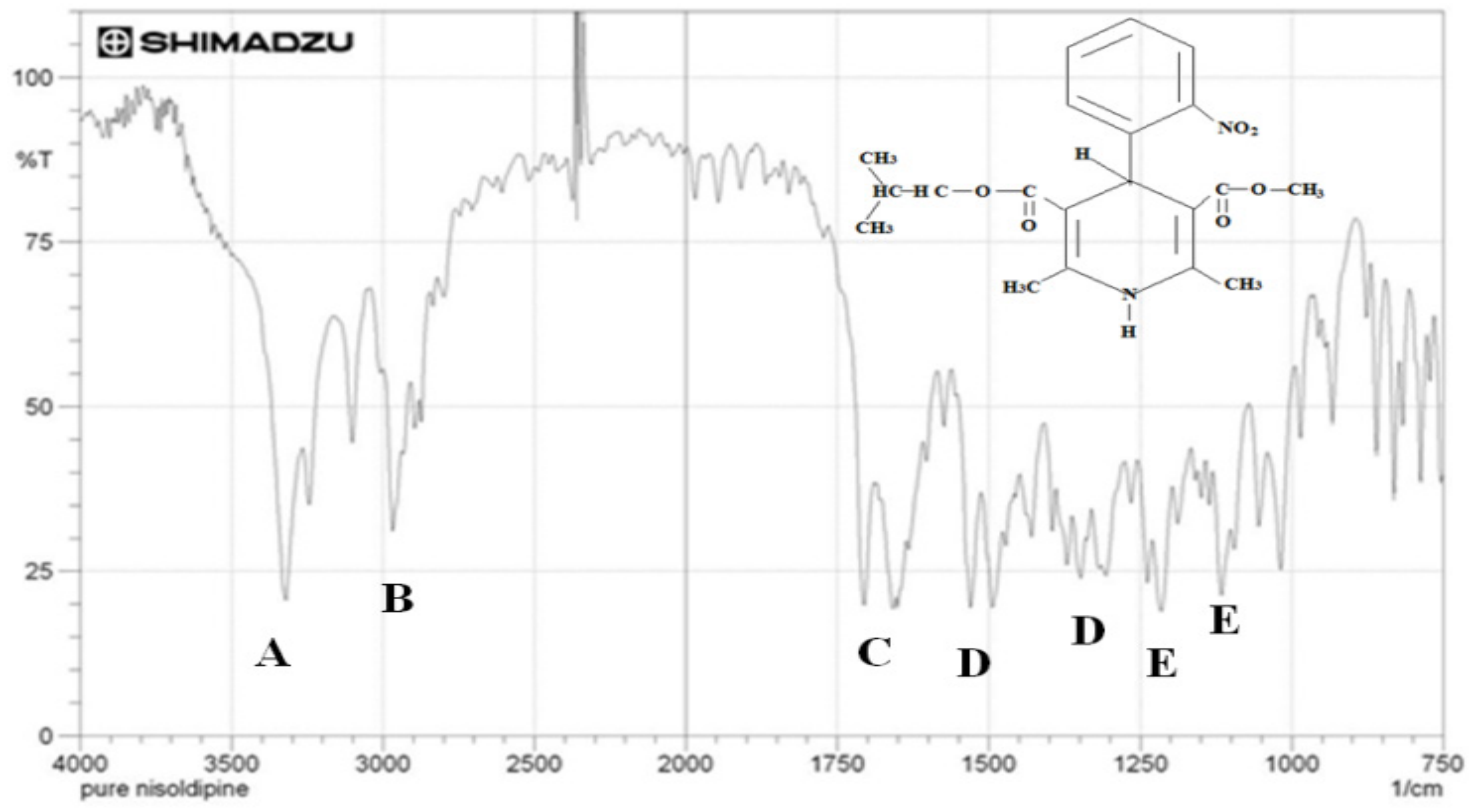

Figure 4. IR spectrum of Nisoldipine

Fig 5 IR spectra of pure pullulan, chitosan, PEG-4000, SSG and D-Mannitol displayed characteristic -OH group at 3334 $\mathrm{cm}^{-1}, 3120 \mathrm{~cm}^{-1}, 3400 \mathrm{~cm}^{-1}, 3280 \mathrm{~cm}^{-1}$ and $3402 \mathrm{~cm}^{-1}$ respectively, while F3 batch tablet (Fig 5) showed superimposition of $-\mathrm{NH}$ group of NSD with that of $-\mathrm{OH}$ functional group of excipients, indicating no inter-molecular drug-excipients interaction. The broadening of $\mathrm{F} 3$ spectrum at $3320 \mathrm{~cm}^{-1}$ and reduction in peak intensity at carbonyl group, nitro group and ether groups suggests significantly polymorphic changes may have occurred due to presence of excipients. 


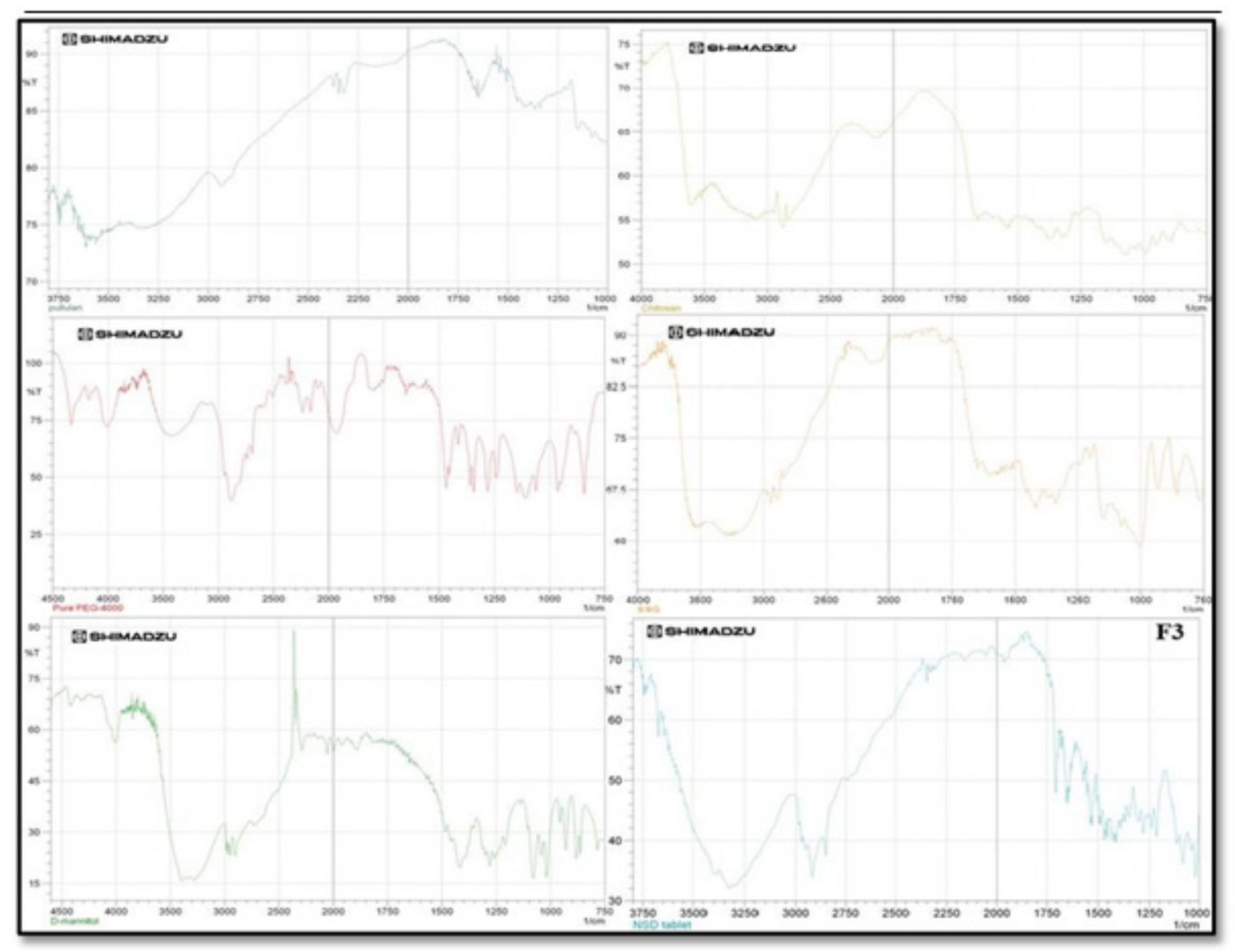

Figure 5. IR Spectra of Pure NSD, Pullulan, Chitosan, PEG-4000, SSG and F3 formulation

\section{In-vitro Dissolution Study}

Fig 6 describes dissolution profile of pure NSD, control formulation F0 and six formulations (F1-F6). Pure NSD exhibited maximum dissolution of $41.90 \%$ in $2 \mathrm{~h}$ due to its highly hydrophobic nature. F0 showed considerable improvement in dissolution of $88.42 \%$ in $1 \mathrm{~h}$, followed by F1, F2 and F3, showing dissolution of $90.56 \%, 94.14 \%$ and $98.45 \%$ in $45 \mathrm{~min}$ respectively. There is tremendous increase in dissolution of F4, F5 and F6 with dissolution of $99.17 \%, 99.98 \%$ and $100.52 \%$ respectively in $30 \mathrm{~min}$. Although maximum drug release was found from F4, F5 \& F6 batch, F3 was considered as optimized batch based on pre-compression parameter and polymer concentration. This significantly increment in dissolution of NSD may be due to combined solubilising effect of pullulan, Chitosan, PEG-6000 and SSG, which may have provoked its solubility and hence dissolution of drug. DSC/XRD/FTIR study have also supported this data

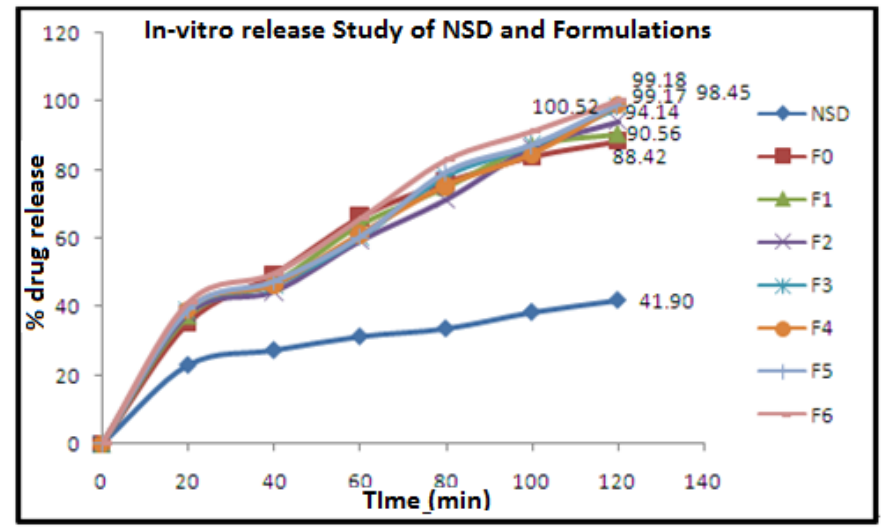

Figure 6. In-vitro dissolution study of Pure NSD and all formulation tablets (F0-F6) 


\section{Conclusion}

NSD sublingual tablets were prepared by using pullulan and chitosan with the aim to enhance solubility \& avoid excessive pre-systemic metabolism which leads to improve bioavailability of drug. All prepared sublingual tablets met the compendia limits in terms of physicochemical parameters, disintegration and dissolution studies. FTIR study reveals that there is no drug-excipients interaction between NSD and excipients. DSC/PXRD study revealed that the crystallinity of NSD was significantly reduced. It is observed that the formulation F3 containing $3 \% \mathrm{w} / \mathrm{w}$ of pullulan and $4 \%$ chitosan was found to be less disintegration time of 34 second, wetting time of 20 second and dissolution rate $(98.45 \%)$ in $45 \mathrm{~min}$ when compared to control formulation (F0) and pure NSD. From this study it can be concluded that, drug having low solubility and low bioavailability due to pre-systemic metabolism can be improve by cost effective, industrial applicable and scalable approach.

\section{Acknowledgements}

The authors are grateful to Emcure Pharmaceutical Ltd, Pune and Gangwal Chemical Pvt. Ltd, Mumbai, for providing gift sample of Nisoldipine \& Pullulan. Authors are also thankful to Dr. Rakesh Patel \& Dr. Girish Patel, Shree S. K. Patel College of Pharmaceutical Education \& Research, Ganpat University to carry out the DSC facility. Authors are also thankful to Dr. S.B. Bari, Principal, H.R Patel Institute of Pharmaceutical Education and Research, Shirpur, Maharashtra, India for providing the necessary facility and their kind support.

\section{Conflict of Interest}

No Conflict of Interest

\section{REFERENCES}

[1] Final Printed Labeling: Sular®. U.S. Department of Health and Human Services, Food and Drug Administration, Center for Drug Evaluation and Research (CDER), U.S. Government Printing Office: Washington, DC. (2000).

[2] Vogt A and Kreuzer H. Arzneim.-Forsc./Drug Res. (1983) 33: 877

[3] Ziya Bayrak, Cetin Tas, Umut Tasdemir, Halil Erol, Cansel Kose Ozkan, Ayhan Savaser, Yalcin Ozkan. Formulation of zolmitriptan sublingual tablets prepared by direct compression with different polymers: In vitro and in vivo evaluation. Eur. J. Pharm. Biopharm. (2011) 78: 499-505.

[4] Wang Y, Zuo Z, Lee KKH and Chow MSS. Evaluation of HO-1-u-1 cell line as an in vitro model for sublingual drug delivery involving passive diffusion-initial validation studies.
Int. J. Pharm. (2007) 334: 27-34.

[5] Yuen S. Pullulan and its applications. Process Biochem. (1974) 9: 7-9.

[6] Jeanes A. Dextrans and pullulans: industrially significant. ACS Symp. Ser. (1977) 45: 284-298.

[7] Craig DQM. The mechanisms of drug release from solid dispersions in water-soluble polymers. Int. J. Pharm. (2002) 231: 131-144.

[8] Leuner C and Dressman J. Improving drug solubility for oral delivery using solid dispersions. Eur. J. Pharm. Biopharm. (2000) 50: 47-60.

[9] Lin CW and Cham TM. Effect of particle size on the available surface area of nifedipine from nifedipine-polyethylene glycol 6000 solid dispersions. Int. J. Pharm. (1996) 127: 261-272.

[10] Liu C and Desai KG. Characteristics of rofecoxib-polyethylene glycol 4000 solid dispersions and tablets based on solid dispersions. Pharm. Dev. Technol. (2005) 10: 467-477.

[11] Urbanetz NA and Lippold BC. Solid dispersions of nimodipine and polyethylene glycol 2000: dissolution properties and physicochemical characterisation. Eur. J. Pharm. Biopharm. (2005) 59: 107-118.

[12] Ahuja N, Katare OP and Singh B. Studies on dissolution enhancement and mathematical modelling of drug release of a poorly water-soluble drug using water soluble carriers. Eur. J. Pharm. Biopharm. (2007) 65: 26-38.

[13] Carter SJ. Eds: In Copper and Gun's: Tutorial Pharmacy, 6th ed., CBS Publishers and Distributors, Delhi (1998) 225.

[14] Aulton ME. Eds: Pharmaceutics: The science of dosage form design, 1st ed., Churchill Livingstone, London (1998) 247.

[15] Basak SC, Selvin CDS and Sabapathy R. Formulation and in-vitro evaluation of amoxicillin dispersible tablets. The Indian Pharmacist (2006) 5(49): 71-73.

[16] Lachman L and Lieber HA. Pharmaeutical dosage forms of tablets. Vol II, Marcel Dekker (1981) 241-243.

[17] Indian Pharmacopoeia. Ministry of Health and Family Welfare. Government of India, Vol II, Delhi (1996) 350.

[18] Chowdhary KPR and Rao NR. Formulation and evaluation of dispersible tablets with pregelatinised starch. Indian Drugs (1998) 35(6): 368-370.

[19] Gupta A, Gaud RS and Ganga S. Development of Discriminatin Dissolution Method for an Insoluble Drug: Nisoldipine. Int.J. PharmTech Res. 2010 2(1): 931-939.

[20] Gamal M. El Maghraby and Ramy N. Elsergany. Fast disintegrating tablets of nisoldipine for intra-oral administration. Pharm Dev Technol (2013), 1-10.

[21] Shruti Chopra, Natarajan Venkatesan and Guru V. Betageri. Formulation of lipid bearing pellets as a delivery system for poorly soluble drugs. International Journal of Pharmaceutics. (2013), 446 (1-2),136-144

[22] Maurya Abhishek R., Chatap Vivekanand K, Deshmukh Prashant K., Mallurwar Vivek R. and Bari Sanjay B. Pullulan as novel solubilizer for solubility enhancement of nisoldipine. Novel Science International Journal of Pharmaceutical Science. (2012), 1(6):374-385. 